\title{
Editorial
}

\section{Abstracts of the 40th Annual Meeting of the Society for Neuropediatrics}

\author{
Martin Staudt ${ }^{1,2}$ Congress President Gesellschaft für Neuropädiatrie \\ ${ }^{1}$ Clinic for Neuropediatrics and Neurorehabilitation, Epilepsy Center \\ for Children and Adolescents, Schön Klinik, Vogtareuth, Germany \\ ${ }^{2}$ Department of Pediatric Neurology and Developmental Medicine, \\ University Children's Hospital, Tübingen, Germany \\ Neuropediatrics
}

For the 40th Annual Meeting of the Society for Neuropediatrics, which takes place as part of the "Neurowoche" in Munich in September 2014, 160 submissions were accepted as free papers for platform presentations or for poster presentations. The English abstracts of these submissions are now published in this online supplement of Neuropediatrics. The first part contains the abstracts of free papers (FP001FP067), sorted by topics which refer to the respective sessions of the conference; the second part consists of the abstracts of posters (P001-P093 sorted alphabetically by first author. Note that the numbering is not consistent with the numbering used in the program of the conference. The abstracts can also be accessed through the "List of Authors"-an online author index-which will be available at: https://www.thiemeconnect.com/products/ejournals/issue/10.1055/s-004-27711 and will assist the reader to get automatically directed to the respective abstract.

On behalf of the Society for Neuropediatrics, I thank the publisher, Georg Thieme Verlag KG, for making our scientific contributions available to the international readership, so that they can receive a broader attention, beyond the participants of the conference.

Please cite the individual abstracts in the following format:

Author names. Abstract title. In: 40th Annual Meeting of the Society for Neuropediatrics; September 17-19, 2014; Munich, Germany: Available at: https://www.thieme-connect.com/ products/ejournals/issue/10.1055/s-004-27711. Neuropediatrics 2014;45(Suppl 1):Abstract Number.
Address for correspondence Prof. Martin Staudt, MD, Clinic for Neuropediatrics and Neurorehabilitation, Epilepsy, Center for Children and Adolescents, Schön Klinik, Krankenhausstrasse 20, D-83569, Vogtareuth, Germany (e-mail: mstaud@schoenkliniken. de).
(C) 2014 Georg Thieme Verlag KG Stuttgart . New York
DOI http://dx.doi.org/ 10.1055/s-0034-1390175. ISSN 0174-304X. 